\title{
Development and validation of stability indicating spectrophotometric and HPTLC methods for determination of acemetacin
}

\author{
Ibrahim Ahmed Naguib a, Eglal Abdelhamid Abdelaleem a, \\ Hala Elsayed Zaazaa ${ }^{b}$ and Essraa Abd ElWahab Hussein ${ }^{a, *}$ \\ a Pharmaceutical Analytical Chemistry Department, Faculty of Pharmacy, Beni-Suef University, 62514, Beni-Suef, Egypt \\ b Analytical Chemistry Department, Faculty of Pharmacy, Cairo University, Kasr El-Aini, 11562 Cairo, Egypt \\ ${ }^{*}$ Corresponding author at: Pharmaceutical Analytical Chemistry Department, Faculty of Pharmacy, Beni-Suef University, 62514, Beni-Suef, Egypt. \\ Tel.: +2.010.08025080. Fax: +2.082.2317950. E-mail address: essraa 88@yahoo.com (E.A.E. Hussein).
}

\section{ARTICLE INFORMATION}

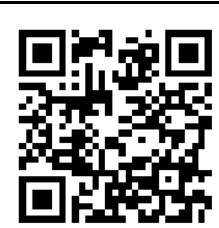

DOI: 10.5155 /eurjchem.5.2.219-226.966

Received: 09 November 2013

Received in revised form: 01 December 2013

Accepted: 05 December 2013

Online: 30 June 2014

\section{KEYWORDS}

HPTLC

Validation

Acemetacin

Degradation

First derivative of ratio spectra

Mean centering of ratio spectra

\section{Introduction}

Acemetacin (ACM), [1-(4-chlorobenzoyl)-5-methoxy-2methylindol-3-yl] acetyloxy acetic acid [1], is a non-steroidal anti-inflammatory drug (NSAID) used in musculoskeletal, joint disorder, rheumatoid arthritis and for treatment of postoperative pain and inflammation [2]. Being a glycolic acid ester of indometacin (NSAID); $50-90 \%$ of absorbed Acemetacin is converted inside the body into indomethacin where both exert their anti-inflammatory action by the same mechanism [3].

The literature survey reveals several methods for determination of Acemetacin in its pharmaceutical preparation including direct UV, derivative UV spectrophotometry and HPLC [4] and micellar liquid chromatograpgy [5]. The effect of micelles on the spectroscopic and solubility properties of the two non-steroidal anti-inflammatory drugs, indomethacin and Acemetacin, was studied at different $\mathrm{pH}$ values [6]. Application of Partial Least Square (PLS) chemometric method for resolving a mixture of Acemetacin and indomethacin mixture was reported [7]. Additionally, it was determined in plasma as well by and HPLC [8-10] and voltammetry [11].

None of the reported methods have described a stabilityindicating method for the determination of ACM in capsule dosage form. Therefore, the aim of this manuscript is to establish and validate stability-indicating methods for the determination of active compound in the presence of its degradation product. To establish the stability-indicating nature of the methods, forced degradation of ACM was performed under stress conditions, and stressed samples were analyzed by use of the proposed spectrophotometric and HPTLC methods, which were able to separate the drugs from compound produced during forced degradation studies.

\section{Experimental}

\subsection{Instruments}

A double beam UV-VIS spectrophotometer (SHIMADZU, Japan) model UV-1601 PC with quartz cell of $1 \mathrm{~cm}$ pathlength, connected to IBM compatible computer. The software was UVPC personal spectroscopy software version 3.7. Data concerning MCR was performed using PLS-Toolbox 2.0 running under MATLAB®, version (R2007b). Camag TLC scanner $3 \mathrm{~S} / \mathrm{N}$ 130319 operated with winCATS software. The following requirements are taken into consideration: Slit dimensions: $6 \times$ $0.3 \mathrm{~mm}$, scanning speed: $20 \mathrm{~mm} / \mathrm{s}$, spraying rate: $10 \mathrm{~s} / \mu \mathrm{L}$, data resolution: $100 \mu \mathrm{m} / \mathrm{step}$, band width: $6 \mathrm{~mm}$, result output: Chromatogram and integrated peak area, Linomat IV with 100 
$\mu \mathrm{L}$ syringe (Camag, Muttenz, Switzerland), HPTLC aluminum plates $(20 \times 20 \mathrm{~cm})$ coated with $0.25 \mathrm{~mm}$ silica gel $60 \mathrm{~F}_{254}$ (Merck, Germany). Sonix TV ss-series ultrasonicator (USA).

\subsection{Material and reagents}

\subsubsection{Pure standard}

ACM was purchased from Sigma-Aldrich through the Egyptian International Center for import and export (EIC, Egypt). Its purity was certified to be $98.00 \%$ according to the company's certificate of analysis. Indomethacin was kindly supplied by Pharco Pharmaceuticals Co., Egypt.

\subsubsection{Pharmaceutical preparation}

Ostmap ${ }^{\circledR}$ capsules batch No (MT 3710911) were manufactured by Multi-Apex Pharmaceutical Industries Co. (Maisons-Alfort, France), each capsule is claimed to contain 60 mg of ACM.

\subsubsection{Chemicals and reagents}

All chemicals and solvents used were of analytical grade, methanol (E. Merck, Germany). Purified water (3A international Co., Kalubia, Egypt). Sodium hydroxide, hydrochloric acid, $30 \%$ hydrogen peroxide solution, hexane, ethyl acetate and glacial acetic acid (El-Nasr Pharmaceutical Chemicals Co., Abu-Zabaal, Cairo, Egypt).

\subsubsection{Degraded sample}

A stock solution containing $0.1 \mathrm{~g}$ of ACM in $100 \mathrm{~mL}$ methanol was prepared. This solution was used for forced degradation under variety of conditions such as: acid and alkaline hydrolysis, oxidation and photodegradation.

Alkaline hydrolysis was performed by adding $5 \mathrm{~mL}$ of $0.1 \mathrm{M}$ $\mathrm{NaOH}$ solution to $5 \mathrm{~mL}$ of ACM stock solution and standing for about 30 minutes at room temperature. Acid hydrolysis was carried out by refluxing with $0.1 \mathrm{M} \mathrm{HCl}$ at $80^{\circ} \mathrm{C}$ for about $4 \mathrm{~h}$. Oxidation studies were implemented using 30\% hydrogen peroxide solution. Finally, photochemical stability was studied by exposing the drug sample to daylight for 24 hours.

Appropriate volume of the resultant solution was applied on TLC plate where complete degradation was followed up via TLC using hexane: ethyl acetate: glacial acetic acid (6:4:0.3, $v: v: v)$ as developing system till complete disappearance of ACM spot. Pure standard of indomethacin solution was used for comparison and its $R_{\mathrm{f}}$ was coinciding with the resultant degradation product (DEG). Furthermore, the degradation product was elucidated by IR and mass spectrometry.

\subsection{Standard solutions}

Stock standard solutions of ACM and DEG $1 \mathrm{mg} / \mathrm{mL}$ of each in methanol. Working standard solutions of ACM and DEG 100 $\mu \mathrm{g} / \mathrm{mL}$ of each in methanol. All stock standard solutions were freshly prepared on the day of analysis and stored in refrigerator to be used within $24 \mathrm{~h}$.

\subsection{Methods}

\subsubsection{Spectrophotometric methods}

\subsubsection{Construction of calibration curve for ${ }^{1} D D$ spectrophotometric method}

Accurately measured aliquots equivalent to $20-220 \mu \mathrm{g}$ of ACM were transferred from its working solution $(100 \mu \mathrm{g} / \mathrm{mL})$ into a series of $10 \mathrm{~mL}$ volumetric flasks. The volume was completed with purified water to obtain a final concentration range $(2-22 \mu \mathrm{g} / \mathrm{mL}) .{ }^{1} \mathrm{DD}$ curves were recorded at $\Delta \lambda=4 \mathrm{~nm}$ and scaling factor $=10$. The absorption spectra of this solution were divided by the absorption spectrum of $20 \mu \mathrm{g} / \mathrm{mL}$ of DEG (as a divisor), and then the obtained ratio spectra were differentiated with respect to wavelength. The peak amplitudes at $244 \mathrm{~nm}$ were recorded then calibration graph was constructed relating the peak amplitudes of $\left({ }^{1} \mathrm{DD}\right)$ to the corresponding concentrations. The regression equation was then computed for the studied drug at the specified wavelength and used for determination of unknown samples containing ACM.

\subsubsection{Construction of calibration curves for mean centering of ratio spectra spectrophotometric method (MCR)}

Accurately measured aliquots equivalent to $20-220 \mu \mathrm{g}$ of ACM were transferred from its working solution $(100 \mu \mathrm{g} / \mathrm{mL})$ into a series of $10 \mathrm{~mL}$ volumetric flasks and the volume was completed with purified water to final concentration range (2$22 \mu \mathrm{g} / \mathrm{mL}$ ).

The recorded absorption spectra of ACM from 220-320 nm were divided by the absorption spectrum of DEG $(20 \mu \mathrm{g} / \mathrm{mL})$ to obtain the ratio spectra, which were then mean centered. These mean centered values of the ratio spectra at $234 \mathrm{~nm}$ were recorded and plotted versus the corresponding concentrations. Calibration curve was constructed and regression equation was computed.

2.4.1.3. Analysis of laboratory prepared mixtures containing different ratios of acemetacin and its degradation product using the suggested methods

Aliquots of intact drug and the DEG were mixed to prepare different mixtures containing $10-90 \%$ of the degradation product, and proceed as mentioned under each method. The concentrations were calculated from the corresponding regression equations.

\subsubsection{HPTLC chromatographic method}

\subsubsection{Construction of calibration curve for HPTLC- densitometric method}

Aliquots equivalent to $0.4-1.4 \mathrm{mg}$ of ACM were transferred from its standard solution $(1 \mathrm{mg} / \mathrm{mL}$ in methanol) into a series of $10 \mathrm{~mL}$ measuring flasks, then the volume of each flask were completed to volume with methanol. $10 \mu \mathrm{L}$ of each solution were applied in triplicate to HPTLC plates $(20 \times 11 \mathrm{~cm})$ as bands with $6 \mathrm{~mm}$ width using a Camag Linomat IV applicator. The bands were spaced $5 \mathrm{~mm}$ from each other and $10 \mathrm{~mm}$ apart from the bottom edge of the plate. Linear ascending development was performed in a chromatographic chamber previously saturated with hexane:ethyl acetate:glacial acetic acid (6:4:0.3, v:v:v) as a developing system for one hour at room temperature to a distance of $9 \mathrm{~cm}$. The integrated peak areas were recorded using scanning wavelength at $254 \mathrm{~nm}$ under the specified instrumental conditions. The calibration curve constructed by plotting the mean integrated peak area $/ 10^{3}$ versus the corresponding concentration of $\mathrm{ACM}$ and then the regression equation was computed.

\subsubsection{Assay of pharmaceutical formulation (Ostmap ${ }^{\circledR}$ capsules)}

The contents of twenty capsules of Ostmap ${ }^{\circledR}$ were weighed and mixed well. An accurately weighed portion equivalent to $100 \mathrm{mg}$ of ACM was transferred into $100 \mathrm{~mL}$ volumetric flask and then $75 \mathrm{~mL}$ methanol was added. The prepared solution was sonicated for $30 \mathrm{~min}$, cooled and completed to volume with methanol. The solution was filtered and diluted to obtain 100 $\mu \mathrm{g} / \mathrm{mL}$ working solution for each method. 


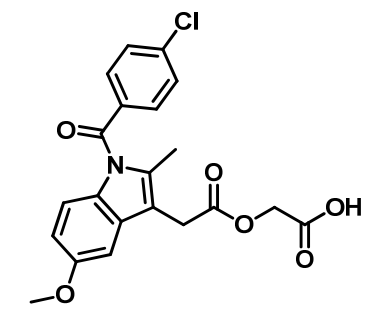

Figure 1. Chemical structure of Acemetacin (ACM).

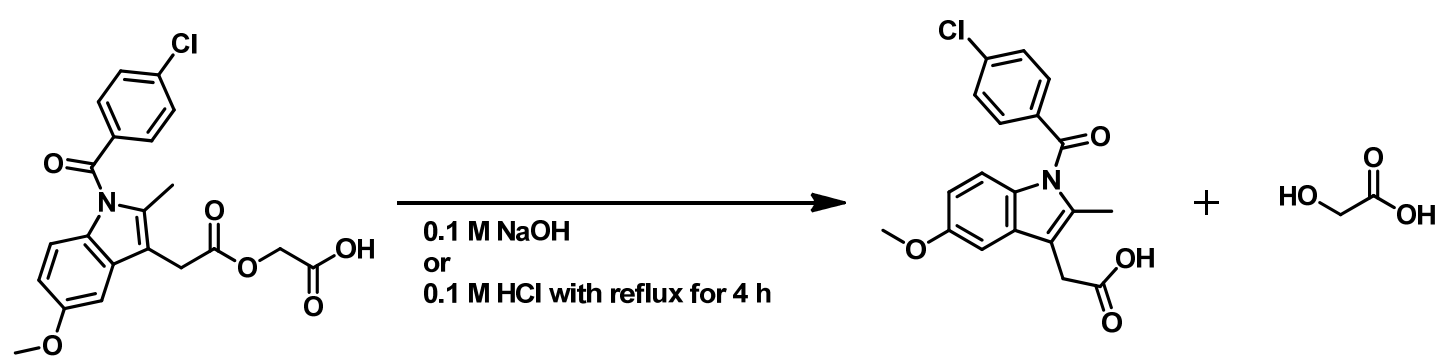

Figure 2. Pathway of ACM hydrolytic degradation.

The procedure detailed under linearity and construction of calibration curve for each method was followed. When carrying out the standard addition technique, the powder content of the capsules and that of pure ACM were mixed well together before proceeding in the above-mentioned procedures.

\section{Results and discussion}

Acemetacin is regarded as a pro-drug of indomethacin [12], both drugs have the same efficiency, but with regard to tolerability, the incidence and severity of gastro-intestinal adverse effects was significantly less with Acemetacin than with indomethacin as it induced more gastric damage, and central nervous system adverse effects were also markedly fewer. So Acemetacin is as effective as indomethacin in the treatment of rheumatoid arthritis, but has significant advantages in terms of tolerability and safety [13]. Thus the main task of this work was to study the stability of ACM according to ICH guidelines [14] for:

(a) Stress alkaline hydrolysis: $0.1 \mathrm{M} \mathrm{NaOH}$ at room temperature for $30 \mathrm{~min}$.

(b) Stress acid hydrolysis: $0.1 \mathrm{M} \mathrm{HCl}$ at $80^{\circ} \mathrm{C}$ for $4 \mathrm{~h}$.

(c) Oxidative condition: $30 \% \mathrm{H}_{2} \mathrm{O}_{2}$ for $24 \mathrm{~h}$.

(d) Photochemical stability was studied by exposing the drug sample to daylight for $24 \mathrm{~h}$.

Being an ester; ACM (Figure 1) was easily hydrolyzed in alkaline medium using $0.1 \mathrm{M} \mathrm{NaOH}$ into corresponding acid; indomethacin. It was also hydrolyzed to the same degradation product by refluxing with $0.1 \mathrm{M} \mathrm{HCl}$ for about $4 \mathrm{~h}$. The resultant solution after both alkaline and acid hydrolysis was compared to the pure standard indomethacin via TLC using hexane: ethyl acetate: glacial acetic acid (6:4:0.3, v:v:v) as developing system. The resultant degradation product was compared with the authentic indomethacin on TLC plate and both shows the same $R_{\mathrm{f}}$ values. Degradation pathway of ACM is shown in Figure 2. ACM showed stability regarding both oxidation and photostability studies.

Moreover, both ACM and DEG were characterized by IRand MS-spectrometry; Figures 3 and 4. IR spectrum of ACM shows four characteristic bands at about 1605.5, 1667.2, $1723.1 \mathrm{~cm}^{-1}$ indicating three carbonyl groups of amide, carboxylic acid and ester respectively [15]. A broad peak appeared at $2937.1 \mathrm{~cm}^{-1}$ indicating the peripheral hydroxyl group [15]. The IR spectrum of DEG indicates the disappearance of the $1723.1 \mathrm{~cm}^{-1}$ ester carbonyl group peak. This result was confirmed by mass spectra, where the MS chart of ACM shows parent peak identified at $\mathrm{m} / \mathrm{z} 415$ (corresponding to the molecular weight of ACM) while MS chart of DEG shows parent peak at $\mathrm{m} / \mathrm{z} 357$ (corresponding to the molecular weight of DEG).

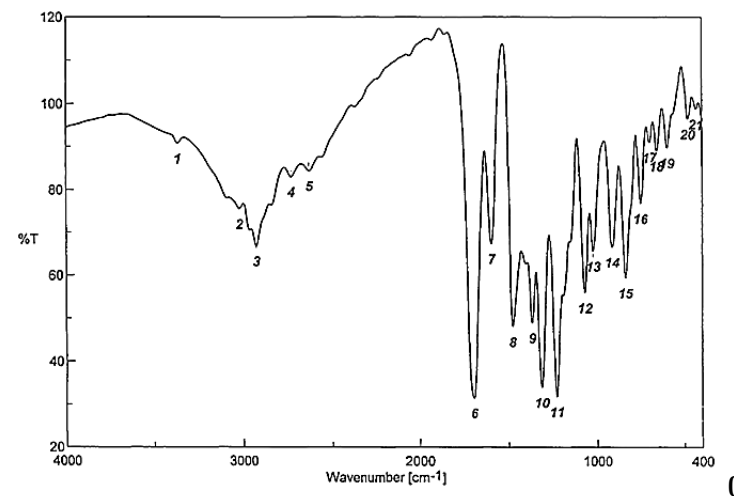

(a)

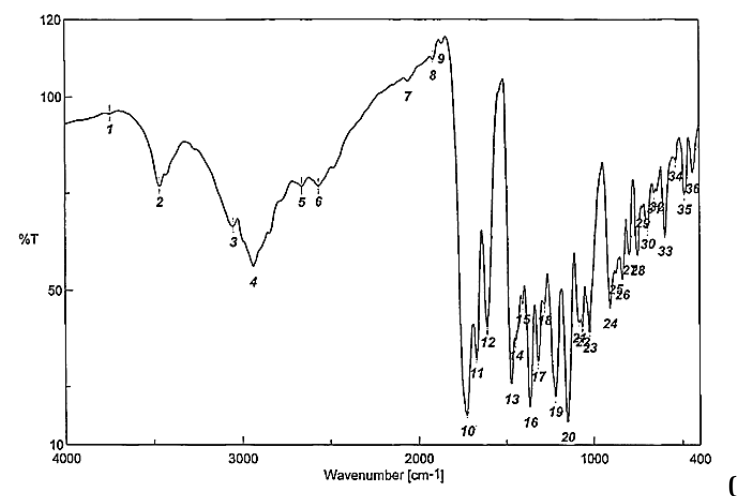

(b)

Figure 3. IR spectra of (a) ACM and (b) DEG. 

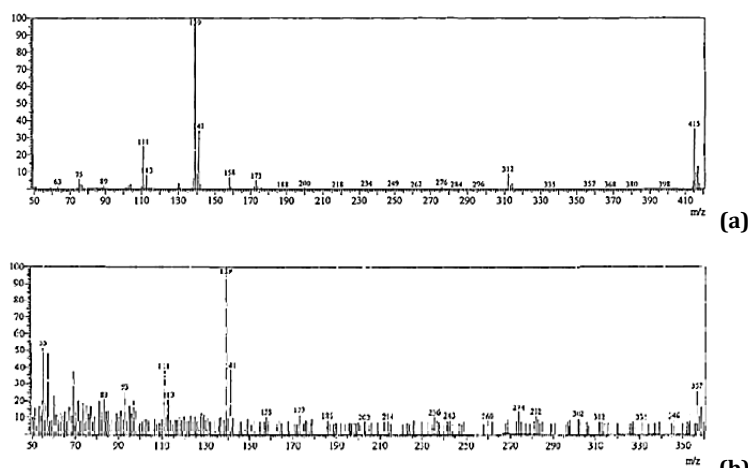

(b)

Figure 4. Mass spectra of (a) ACM and (b) DEG.

\subsection{Spectrophotometric methods}

\subsection{1. ${ }^{1 D D}$ spectrophotometric method}

The zero-order absorption spectra of ACM and its DEG show sever or even complete overlapping (Figure 5), which interferes with the direct spectrophotometric determination of ACM in presence of its DEG. Derivative ratio spectroscopy is an analytical technique of great utility for resolving overlapped spectra, by applying this technique selective determination of ACM in presence of DEG was achieved by measuring the peak amplitude at $244 \mathrm{~nm}$ as shown in Figure 6.

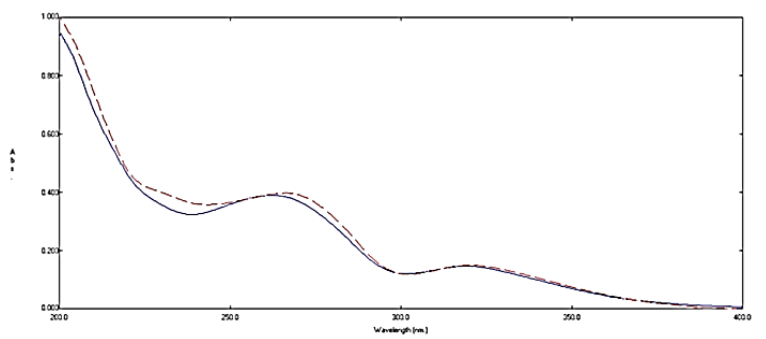

Figure 5. Zero order absorption spectra of $8 \mu \mathrm{g} / \mathrm{mL}$ of ACM (-) and 8 $\mu \mathrm{g} / \mathrm{mL}$ of DEG (---) using purified water as a blank.

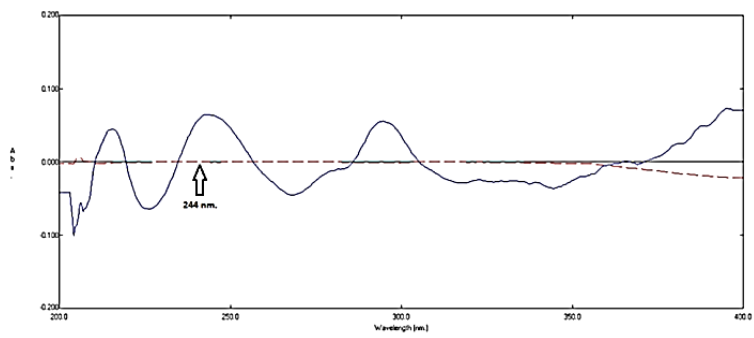

Figure 6. First derivative of the ratio spectra of $16 \mu \mathrm{g} / \mathrm{mL}$ of ACM (-) and $16 \mu \mathrm{g} / \mathrm{mL}$ of DEG (-- ) using $20 \mu \mathrm{g} / \mathrm{mL}$ of DEG as divisor and purified water as a blank.

\subsubsection{Mean centering of ratio spectra spectrophotometric method (MCR)}

The developed MCR method depends on the mean centering of the ratio spectra, it eliminates the derivative steps and so signal-to-noise ratio is enhanced [16]. It has been applied for resolving binary and ternary mixtures in complex samples with unknown matrices [17]. The mathematical explanation of the method was obtained and illustrated by Afkhami and Bahram [18].
The main step in the development of an analytical method is to optimize the conditions and parameters, which will be followed in development and validation to obtain the best results. To optimize the ${ }^{1} \mathrm{DD}$ and mean centering spectrophotometric methods, it was necessary to test the influence of the following variables:

\subsubsection{Solvents}

Different solvents were studied (methanol, ethanol, isopropanol, acetonitrile, purified water, $0.1 \mathrm{M} \mathrm{HCl}$ and $0.1 \mathrm{M}$ $\mathrm{NaOH}$ ). It was found that purified water was the best solvent regarding selectivity and sensitivity.

\subsubsection{The divisor and its concentration}

The effect of divisor concentration on the method selectivity and analytical parameters such as slope, intercept and correlation coefficient of calibration equations was tested. Different concentrations of DEG were tested as a divisor (2, 4, $6,8,16,20 \mu \mathrm{g} / \mathrm{mL}$ ). It was found that $20 \mu \mathrm{g} / \mathrm{mL}$ of DEG was the best regarding selectivity and sensitivity.

\subsubsection{Smoothing and scaling factors}

Different smoothing factor $(\Delta \lambda)$ values were tried, where smoothing factor $=4$ showed a suitable signal to noise ratio with good resolution. Different scaling factor values were tried where scaling factor $=10$ was the best to measure the signal of ACM and to decrease the reading error.

The peak amplitude of the first derivative of ratio spectra at $\lambda=244 \mathrm{~nm}$ (as shown in Figure 7) was plotted versus the concentration of ACM in the range of $2-22 \mu \mathrm{g} / \mathrm{mL}$. The calibration curve was constructed with mean percentage recovery $99.65 \% \pm 0.797$. The following linear regression equation was obtained:

$\mathrm{Y}=0.0039 \mathrm{C}+0.0024, r=0.9999$

where $\mathrm{Y}$ is the peak amplitude at $244 \mathrm{~nm}, \mathrm{C}$ is the concentration in $\mu \mathrm{g} / \mathrm{mL}$ and $r$ is the correlation coefficient.

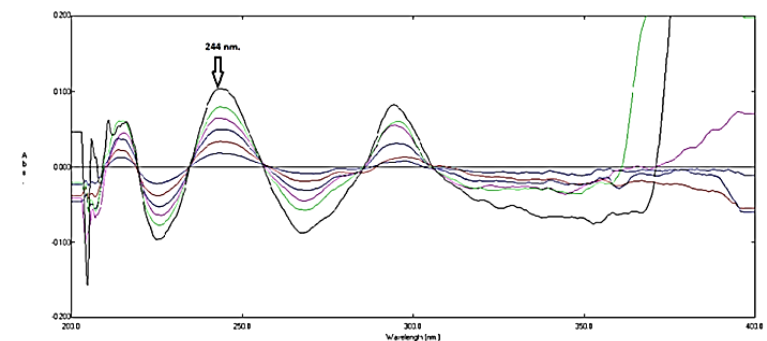

Figure 7. First derivative of ratio spectra of of ACM in the range of 2-22 $\mu \mathrm{g} / \mathrm{mL}$ using $20 \mu \mathrm{g} / \mathrm{mL}$ DEG as a divisor purified water as blank.

While the absorption spectra of ACM were recorded in the wavelength range of 220-320 $\mathrm{nm}$ and divided by the absorption spectrum DEG $(20 \mu \mathrm{g} / \mathrm{mL})$ to obtain the ratio spectra which were then mean centered. ACM was determined by measuring the peak amplitude at $234 \mathrm{~nm}$ which corresponds to maximum wavelength as shown in Figure 8. The peak amplitude was plotted versus the corresponding concentration in the range of $2-22 \mu \mathrm{g} / \mathrm{mL}$. The calibration curve was constructed with mean percentage recovery $99.30 \% \pm 1.146$. The following linear regression equation was obtained:

$\mathrm{Y}=0.003 \mathrm{C}+0.003, r=0.9999$

where $\mathrm{Y}$ is the peak amplitude at $234 \mathrm{~nm}, \mathrm{C}$ is the concentration in $\mu \mathrm{g} / \mathrm{mL}$ and $r$ is the correlation coefficient. 


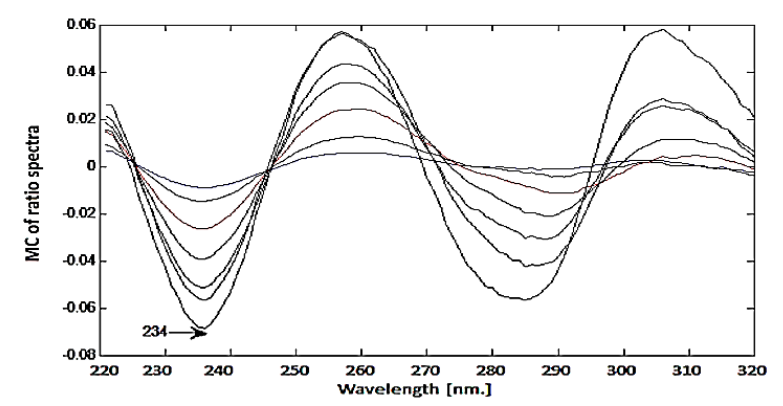

Figure 8. The mean centered ratio absorption spectra of ACM in the range of $2-22 \mu \mathrm{g} / \mathrm{mL}$ using purified water as a blank.

\subsection{HPTLC method}

Thin layer chromatography (TLC) made a great progress and attained a wide acceptance as a major analytical tool for both qualitative and quantitative methods of analysis and became a well established method for the assay of drugs in mixtures. HPTLC offers the advantages of automatic application, high separation and giving dense and compact spots with appropriately and significantly different $R_{\mathrm{f}}$ values in addition to high sensitivity [19]. Accordingly, HPTLC method was successfully applied for separation of ACM and DEG mixture and for quantification of ACM in presence of its DEG in pure form and in pharmaceutical preparation.

In order to optimize the developed HPTLC method, it was necessary to investigate the effect of different factors to get the desired chromatographic resolution.

\subsubsection{Developing system and efficiency}

Different developing systems of different composition and ratios were tried such as chloroform:methanol $(9: 1, v: v)$, chloroform:methanol:ammonia solution (9:1:0.1, $v: v: v)$, chloroform:methanol:glacial acetic acid (9:1:0.1, v:v:v), and hexane:ethyl acetate:glacial acetic acid $(6: 4: 0.3, v: v: v)$ to obtain optimum separation between ACM and its degradation product (DEG). The best developing system was found to be hexane:ethyl acetate:glacial acetic acid (6:4:0.3, v:v:v). This selected developing system allowed good separation between ACM and its degradation product with satisfactory Rf values without tailing of the separated bands, as shown in Figure 9. It was found that presence of glacial acetic acid with this ratio in the developing system is essential for separation.

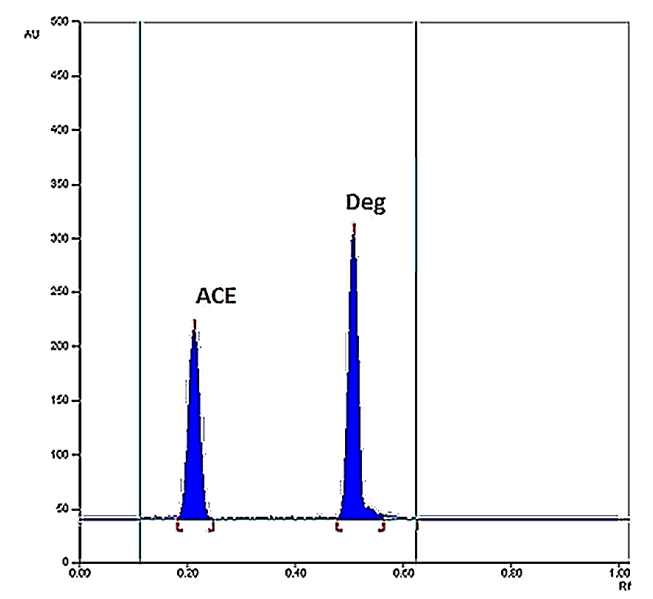

Figure 9. 2D HPTLC densitogram of resolved mixtures of ACM $\left(R_{\mathrm{f}}=0.21\right)$ and DEG $\left(R_{\mathrm{f}}=0.51\right)$ using (hexane:ethyl acetate:glacial acetic acid) $(6: 4: 0.3, v: v: v)$ as a developing system at $254 \mathrm{~nm}$.

\subsubsection{Scanning wavelength}

Different scanning wavelengths were tried $(254,265$ and $318 \mathrm{~nm}$ ) in order to obtain good sensitivity of ACM with minimum noise. The wavelength $254 \mathrm{~nm}$ was found to be the best wavelength regarding sensitivity of ACM. Peaks were sharp and symmetrical with minimum noise, as shown in Figure 10.

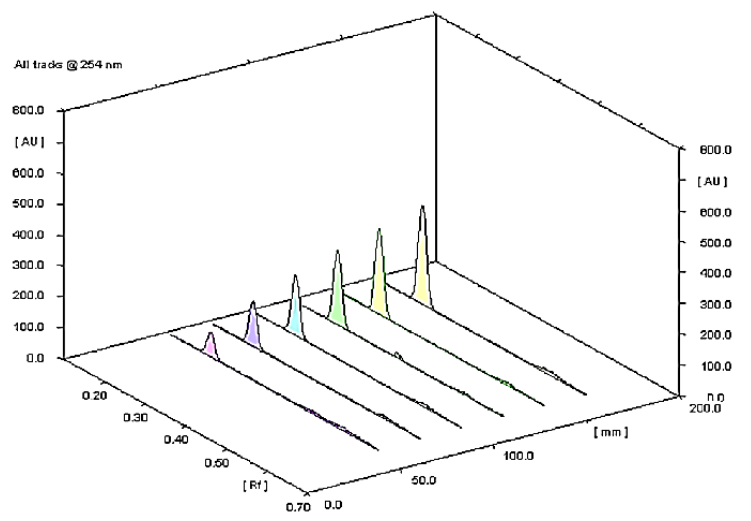

Figure 10. HPTLC densitogram of ACM in the concentration range (0.4-1.4 $\mu \mathrm{g} / \mathrm{band}$ ) using (hexane:ethyl acetate:glacial acetic acid) solution (6:4:0.3, $v: v: v$ ) as a developing system at $254 \mathrm{~nm}$.

\subsubsection{Band dimensions}

The slight spread of the developed bands due to ordinary diffusion should be taken into consideration, so the band width and interspaces between bands should be chosen carefully to avoid spread of bands outside the scanning tracks and interference between adjacent bands. Different band dimensions were tried to obtain sharp and symmetrical peaks. The optimum bandwidth chosen was $6 \mathrm{~mm}$ and the inter-space between bands was $5 \mathrm{~mm}$.

\subsubsection{Slit dimensions of scanning light beam}

The slit dimensions of the scanning light beam should ensure complete coverage of band dimensions on the scanned track without interference of adjacent bands. Different slit dimensions were tried where $6 \mathrm{~mm} \times 0.3 \mathrm{~mm}$ proved to be the slit dimensions of choice which provided highest sensitivity.

This method offers high sensitivity and selectivity for analysis of ACM in presence of DEG using hexane: ethyl acetate: glacial acetic acid $(6: 4: 0.3, v: v: v)$ as a developing system, where good separation was obtained by the difference in the retention factor $\left(R_{\mathrm{f}}\right)$ values of ACM $\left(R_{\mathrm{f}}=0.21\right)$ and DEG $\left(R_{\mathrm{f}}=0.51\right)$ as shown in Figure 9.

The calibration curve for ACM was constructed by plotting the integrated peak area $/ 10^{3}$ versus the corresponding concentrations of ACM in the range of $0.4-1.4 \mu \mathrm{g} / \mathrm{band}$ with mean percentage recovery $100.00 \pm 0.709$. The concentration of ACM was calculated from the following regression equation:

$\mathrm{A}=0.1944 \mathrm{C}+0.0671, r=0.9999$

where $\mathrm{A}$ is integrated peak areas $/ 10^{3}, \mathrm{C}$ is the concentration in $\mu \mathrm{g} / \mathrm{band}$ and $r$ is the correlation coefficient.

\subsection{Stability-indication}

To assess the stability-indicating efficiency of the proposed methods, they were applied to laboratory prepared mixtures containing different ratios of ACM and DEG. 
Table 1. Assay results for the determination of ACM in synthetic mixtures with DEG.

\begin{tabular}{lll}
\hline \multirow{2}{*}{ \%EG \% } & \% Recovery & \% Recovery \\
\cline { 2 - 3 } & 1DD spectrophotometric method & Mean centering method \\
\hline $10 \%$ & 100 & 99.60 \\
$20 \%$ & 101.9 & 101.60 \\
$30 \%$ & 101.1 & 100.30 \\
$40 \%$ & 98.85 & 99.17 \\
$50 \%$ & 98.97 & 99.00 \\
$60 \%$ & 101.9 & 102.50 \\
$70 \%$ & 100.9 & 97.18 \\
$80 \%$ & 97.44 & 98.31 \\
$90 \%$ & $93.59^{*}$ & 101.90 \\
Mean \pm SD & $100.13 \pm 1.610$ & $99.96 \pm 1.780$ \\
\hline
\end{tabular}

* Rejected value

Table 2. Determination of ACM in pharmaceutical formulation by the proposed methods and application of standard addition technique.

\begin{tabular}{|c|c|c|c|c|}
\hline \multirow[t]{2}{*}{ Pharmaceutical formulation } & \multicolumn{4}{|c|}{$\begin{array}{l}\text { Ostmap® capsules } \\
\text { B.N: } 3710911\end{array}$} \\
\hline & Taken $(\mu \mathrm{g} / \mathrm{mL})$ & Found $\% * \pm$ SD & Pure added $(\mu \mathrm{g} / \mathrm{mL})$ & Recovery \% \\
\hline \multirow[t]{4}{*}{${ }^{1 D D}$ method } & \multirow[t]{3}{*}{10.00} & \multirow[t]{3}{*}{$101.23 \pm 1.008$} & 8.00 & 99.04 \\
\hline & & & 10.00 & 100.3 \\
\hline & & & 12.00 & 97.22 \\
\hline & Mean \pm SD & & & $98.84 \pm 1.527$ \\
\hline \multirow{4}{*}{$\begin{array}{l}\text { Mean centring spectrophotometric } \\
\text { method }\end{array}$} & \multirow[t]{3}{*}{10.00} & \multirow[t]{3}{*}{$101.28 \pm 1.758$} & 8.00 & 101.48 \\
\hline & & & 10.00 & 101.55 \\
\hline & & & 12.00 & 100.89 \\
\hline & Mean \pm SD & & & $101.31 \pm 0.359$ \\
\hline \multirow[t]{4}{*}{ HPTLC method } & \multirow[t]{3}{*}{0.60} & \multirow[t]{3}{*}{$99.88 \pm 1.004$} & 0.40 & 101.6 \\
\hline & & & 0.60 & 98.83 \\
\hline & & & 0.80 & 97.4 \\
\hline & \multicolumn{2}{|l|}{ Mean \pm SD } & & $99.28 \pm 2.139$ \\
\hline
\end{tabular}

* Average of 6 determinations.

Table 3. Regression and validation parameters of the proposed methods for determination of ACM in presence of DEG. Parameter 1DD spectrophotometric method Mean centering method Slope $\quad 2-22 \mu \mathrm{g} / \mathrm{mL}$

Intercept

0.0024

Correlation coefficient (r) $\quad 0.9999$

Accuracy $\quad 99.65 \% \pm 0.797$

Specificity and Selectivity $\quad 100.13 \pm 1.61$

Precision

Repeatability (RSD\%) a $\quad 0.318-0.056$

Intermediadte Precision (RSD\%) a $\quad 0.275-0.450$

LOD b $\quad 0.379 \mu \mathrm{g} / \mathrm{mL}$

LOQ ${ }^{b} \quad 1.147 \mu \mathrm{g} / \mathrm{mL}$

Robustness

\begin{tabular}{ll} 
Mean centering method & HPTLC method \\
\hline $2-22 \mu \mathrm{g} / \mathrm{mL}$ & $0.4-1.4 \mu \mathrm{g} / \mathrm{b}$ and \\
0.0030 & 0.1944 \\
0.0030 & 0.0671 \\
0.9999 & 0.9999 \\
$99.30 \% \pm 1.146$ & $100.00 \% \pm 0.709$ \\
$99.96 \pm 1.780$ & - \\
& \\
$0.037-0.099$ & $0.341-1.358$ \\
$0.057-0.910$ & $2.828-2.805$ \\
$0.407 \mu \mathrm{g} / \mathrm{mL}$ & $0.050 \mu \mathrm{g} / \mathrm{band}$ \\
$1.232 \mu \mathrm{g} / \mathrm{mL}$ & $0.400 \mu \mathrm{g} / \mathrm{band}$
\end{tabular}

a (RSD\%) and (RSD\%); the intra- and inter-day relative standard deviation of concentrations $(6,20 \mu \mathrm{g} / \mathrm{mL})$ for ${ }^{1} \mathrm{DD}$ method, $(4,12 \mu \mathrm{g} / \mathrm{mL})$ for $\mathrm{MCR}$ method and $(0.6,1.2 \mu \mathrm{g} / \mathrm{band})$ for HPTLC method.

${ }^{b}$ Limit of detection and quantitation are determined via calculations for ${ }^{1} \mathrm{DD}$ and MCR methods (LOD $=3.3 \times \mathrm{SD} /$ slope, LOQ $=10 \times \mathrm{SD} /$ slope $)$ and experimentally by signal-to-noise ratio for HPTLC method [20].

Results given in Table 1 indicate that the proposed $1 \mathrm{DD}$ method is valid for determination of intact ACM in presence of up to $80 \%$ of its DEG and mean centering method is selective and valid for determination of ACM in presence of up to $90 \%$ of its DEG.

As the suggested methods could effectively determine the drug in presence of its DEG, they can be employed as stability indicating ones.

\subsection{Application of the proposed methods to the pharmaceutical formulation}

The suggested methods were successfully applied for the determination of ACM in its pharmaceutical formulation (Ostmap® capsules), showing good percentage recoveries. The validity of the suggested methods was further assessed by applying the standard addition technique as shown in Table 2.

\section{Methods validation}

Methods validation was performed according to the international conference on harmonization (ICH) guidelines [20] for the proposed methods.

\subsection{Linearity}

Under optimum experimental conditions, ACM was determined in triplicates in the range of $2-22 \mu \mathrm{g} / \mathrm{mL}$ for ${ }^{1} \mathrm{DD}$ and MCR methods and in the range of $0.4-1.4 \mu \mathrm{g} / \mathrm{band}$ for HPTLC method, Table 3.

\subsection{Range}

The specified range is derived from linearity studies and depends on the application of analytical procedure. The concentration of ACM present in pharmaceutical preparation gave accurate and precise results with the suggested methods as shown in Table 3.

\subsection{Accuracy}

Accuracy was assessed by the standard addition technique and through analysis of market pharmaceutical preparation by the proposed methods. The resulting synthetic mixtures (of pure drug portions added to dosage form) were assayed and the found concentration of pure drug portions were compared to those expected. The good recoveries of pure drug samples suggest good accuracy of the proposed methods, Table 2. 
Table 4. Parameters of system suitability of the developed HPTLC method for the determination of ACM in presence of DEG.

\begin{tabular}{lll}
\hline Parameters & ACM & DEG \\
\hline Capacity factor $\left(K^{\prime}\right)$ & 2 & 6 \\
Symmetry factor & 1.03 \\
Resolution $\left(\mathrm{R}_{\mathrm{s}}\right)$ & 6.62 \\
Selectivity $(\alpha)$ & 2.43 \\
\hline
\end{tabular}

Table 5. Statistical analysis of the three proposed methods (1DD spectrophotometric method, Mean centering method and HPTLC method) and the reported HPLC method for determination of ACM in Ostmap® capsules.

\begin{tabular}{lllll}
\hline Parameters & 1DD spectrophotometric method & Mean centering method & HPTLC method & Reported HPLC method a \\
\hline Mean & 101.23 & 101.28 & 99.88 & 1.004 \\
SD & 1.008 & 1.758 & 1.008 & 1.682 \\
Variance & 1.0151 & 3.091 & 6 & 2.830 \\
n & 6 & 6 & 0.006 & 6 \\
Student's $t$-test b $^{\text {b }}$ (2.228) & 0.075 & 0.142 & 2.807 & - \\
F-test b $(5.050)$ & 2.788 & 1.092 & - \\
\hline
\end{tabular}

a HPLC determination of ACM using acetonitrile:water $(80: 20, \mathrm{v}: \mathrm{v})$ as mobile phase and UV detection at $280 \mathrm{~nm}[4]$.

$\mathrm{b}$ The values between parenthesis are corresponding to the theoretical values of $t$ and $F(p=0.05)$.

\subsection{Precision}

\subsubsection{Repeatability}

Two concentrations of ACM $(6,20 \mu \mathrm{g} / \mathrm{mL})$ for ${ }^{1} \mathrm{DD}$ method, $(4,12 \mu \mathrm{g} / \mathrm{mL})$ for MCR method and $(0.6,1.2 \mu \mathrm{g} / \mathrm{band})$ for HPTLC method were determined in triplicates in the same day to estimate intraday variation. Good results and acceptable relative standard deviation (RSD\%) are shown in Table 3.

\subsubsection{Intermediate precision}

The previous procedures were repeated on the same concentrations seven times on different four days to determine the intermediate precision. Good results and acceptable relative standard deviation (RSD\%) shown in Table 3.

\subsection{Specificity}

It was evaluated by analysis of different synthetic laboratory prepared mixtures containing different ratios of ACM spiked with appropriate levels of DEG. Demonstrating that the assay results are unaffected by the presence of DEG prove specificity of the methods as shown in Table 1.

\subsection{Detection and quantitation limits}

For spectrophotometric methods (1DD and MCR), the approach based on the standard deviation of the response and the slope was used for determining the detection and quantitation limits, Table 3.

LOD $=3.3 \times$ SD/slope $[20]$

$\mathrm{LOQ}=10 \times \mathrm{SD} /$ slope $[20]$

For HPTLC method, as it exhibits baseline noise, the detection limit is determined by signal-to-noise ratio. Determination of signal- to-noise ratio is made by comparing the measured signals of samples with known low concentrations of analyte with those of blank samples. For detection limit, determine the minimum concentration at which the analyte can be detected. For quantitation limit, determine the minimum concentration at which the analyte can be quantified [20]. Acceptable detection and quantitation limits are shown in Table 3.

\subsection{Robustness}

The robustness of an analytical procedure is a measure of its capacity to remain unaffected by small deliberate variations in method parameters and provides an indication of its reliability during normal usage.

For HPTLC method, the organic strength of the developing system was deliberately changed by $\pm 0.5 \mathrm{~mL}$ and it has no significant effect on $R_{\mathrm{f}}$ values or symmetry of the peaks as shown in Table 3. However, small changes in the volume of glacial acetic acid greatly affect separation of DEG.

\subsection{System suitability}

ICH states that system suitability tests are an integral part of many analytical methods, especially liquid chromatographic methods. They are used to verify that the resolution and reproducibility of the chromatographic system are adequate for the analysis to be done. Parameters including resolution $\left(R_{\mathrm{s}}\right)$, capacity factor $\left(\mathrm{k}^{\prime}\right)$, peak symmetry and selectivity factor $(\alpha)$ were calculated as shown in Table 4.

The results obtained by the proposed methods were statistically compared with those obtained by the reported HPLC method using $t$ - and $F$ - tests. The values obtained are less than the theoretical ones indicating that there is no significant difference between the proposed methods and the reported HPLC method with respect to accuracy and precision, Table 5.

\section{Conclusion}

The present work introduces simple, sensitive and rapid methods that are performed to determine ACM in pure form and in pharmaceutical preparation. The spectrophotometric methods are simple, less time consuming and economic stability indicating method compared to published LC methods. Compared to the derivative method, MCR eliminates the derivative step and so the signal-to-noise ratio is enhanced. Moreover, it was more selective than the ${ }^{1} \mathrm{DD}$ spectrophotometric method.

The HPTLC method has the advantage that several samples can be run simultaneously using a small quantity of developing system. It can provide high sensitivity and selectivity, in addition to separation of ACM from DEG.

The proposed methods showed high sensitivity, accuracy, reproducibility and selectivity. Moreover, these methods can be used as stability indicating methods. These merits suggest the use of the proposed methods in routine and quality control analysis without interference of commonly encountered pharmaceutical preparation additives.

\section{References}

[1]. Maryedele, J. O'Neil, The Merck Index, An Encyclopedia of Chemicals, Drugs and Biologicals, $14^{\text {th }}$ ed., Merck and Co. Inc., Whitehouse Station, NJ, USA.

[2]. Reynolds, J. E. F., Martindale, The Extra Pharmacopoeia. Thirsty-first ed.; Royal Pharmaceutica Society: London, 1996. 
[3]. Li, D. M.; Lu, W. L.; Wang, X. Q.; Wang, J. C.; Zhang, H.; Zhang, R. J.; Wang, G.L.; Zhang, X.; Zhang, Q. J. Health Sci. 2005, 51(3), 308-316.

[4]. Ozbakan, H.; Palabiyik, I. M.; Caglayan, M. G.; Feyyaz, O. Turk J. Pharm. Sci. 2009, 6(3), 163-176.

[5]. Escuder-Gilabert, L.; Martin-Biosca, Y.; Sagrado, S.; VillanuevaCamanas, R.; Medina-Hernandez, M. Chromatographia 2002, 55(5-6), 283-288.

[6]. Castro, B.; Gameiro, P.; Lima, J. L.; Matos, C.; Reis, S. Mater. Sci. Eng. C 2001, 18(1), 71-78.

[7]. Arcos, M. J.; Ortiz, M. C.; Villahoz, B. N.; Sarabia, L. A. Anal. Chim. Acta 1997, 339(1), 63-77.

[8]. Pang, J.; Hengshan, T. Zhongguo Yiyuan Yaoxue Zazhi 2004, 24(4), 246-247.

[9]. Shi, X.; Chen, M.; Zhang, J.; Zhang, L.; Wang, H. Zhongguo Yiyao Zazhi 2001, 32(10), 454-456.

[10]. Hu, Y. Q.; Liu, H. C.; Ma, R.; Wang, J.; Hou, Y. N. Se Pu 1999, 17(6), 586587.

[11]. Reguera, C.; Julia Arcos, M.; Cruz Ortiz, M. Talanta 1998, 46(6), 14931505.

[12]. Chavez-Pina, W. M.; Dicay, M.; Castaneda-Hernandez, G.; Wallace, J.L. Brit. J. Pharmacol. 2007, 152(6), 930-938.

[13]. Saul PA, K. K. Curr. Med. Res. Opin. 1991, 12(5), 332-341.

[14]. Bakshi, M.; Singh, S. J. Pharmaceut. Biomed. 2002, 28(6), 1011-1040.

[15]. Donald, L. P.; George S. K. Introduction to Spectroscopy. Western Washington University: Bellingham, Washington, USA, 2009.

[16]. Afkhami, A.; Bahram, M. Anal. Chim. Acta 2004, 526(2), 211-218.

[17]. Afkhami, A.; Bahram, M. Talanta 2005, 66(3), 712-720.

[18]. Afkhami, A.; Bahram, M. Talanta 2006, 68(4), 1148-1155.

[19]. Desai, N.; Amin, P. I. J. Pharm. Sci. 2008, 70(5), 644-647.

[20]. ICH, Q2 (R1) Validation of Analytical Procedures: Text and Methodology, ICH Harmonized Tripartite Guideline, 2005. Guideline, I.H.T., Validation of Analytical Procedures: Text and Methodology, Q2 (R1) Geneva, 2005. 